\title{
ANISTIAS COMO PRÁTICA DO DIREITO INTERNACIONAL CRIMINAL E A COMPLEMENTARIDADE DO TRIBUNAL PENAL INTERNACIONAL
}

\author{
Rui Carlo Dissenha ${ }^{1}$
}

\section{RESUMO}

O conceito de complementaridade é uma das bases do Estatuto de Roma e se manifesta com duas conseqüências maiores: primeiramente, confirma a soberania dos Estados membros do tratado conferindo-lhes primazia jurisdicional na aplicação da justiça criminal aos crimes de competência do TPI; em segundo lugar, funciona como instância de controle da aplicação da jurisdição criminal pelos tribunais nacionais, verificando-lhes a correição frente a parâmetros internacionalmente aceitos. Todavia, nesse exercício o TPI pode se defrontar com anistias - figuras comuns no Direito Internacional Penal - como forma de solução de conflitos nacionais em lugar da persecução jurisdicional. Muitas dessas anistias, embora impliquem o esquecimento dos crimes cometidos, são os elementos que garantem a estabilidade social e a paz em situações de pós-conflito. Assim, o TPI deverá decidir se tal expediente (que valoriza a paz em detrimento da justiça) é suficiente para barrar a sua atuação. Quando, excepcionalmente, anistias forem concedidas com base em processos de busca pela verdade e reconstrução social, parece possível que possam afastar a jurisdição internacional. Todavia, quando tais anistias não forem mais do que uma simples evasão à punição criminal, é certo que a Corte de Roma deverá exercer sua jurisdição aplicando a lei internacional ao caso concreto.

\footnotetext{
1 Professor universitário. Diplôme Supérieur de l'Université pela Université de Paris II Panthéon-Assas, França. Mestre em Direito das Relações Sociais pela Universidade Federal do Paraná. LLM (advanced) in Public International Law with International Criminal Law Specialization pela Leiden University, Holanda. Todas as citações em língua estrangeira estão traduzidas pelo próprio autor. O autor gostaria, ainda, de agradecer as preciosas sugestões e correções oferecidas por Melissa Martins Casagrande. Os erros, todavia, são oponíveis apenas ao próprio autor.
}

Revista Brasileira de Direito Internacional, Curitiba, v.1, n.1, jan./jun.2005 


\section{ABSTRACT}

Complementarity is one of the pillars of the Rome Statute and has two main consequences: firstly, it confirms the sovereignty of States parties to the treaty by granting them the right to judge their own criminals responsible for international crimes; and secondly, it works as an instance of control of national criminal jurisdiction, scrutinizing its adequacy in comparison to international accepted parameters. However, the ICC will soon face the question of amnesties - a very common occurrence in international criminal law - applied in place of persecution of international crimes. Many of those amnesties, although implying the consignment to oblivion of committed crimes, help to guarantee social stability and peace in post-conflict situations. Here, the ICC will be obliged to decide whether such a mechanism (which strengthens peace while weakens justice) can impede its seizing of the case. When, in special situations, those amnesties are granted through truth searching processes aiming at social rebuilding, it seems possible that they are able to impede international jurisdiction. Nevertheless, when those amnesties are designed only to grant jurisdictional immunity to international criminals, it seems right to say that the ICC will exercise its jurisdiction, through the complementarity principle, applying international law and pursuing justice.

PALAVRAS-CHAVE: Tribunal Penal Internacional, Complementaridade, Anistia.

KEYWORDS: International Criminal Court, Complementarity, Amnesty.

\section{INTRODUÇÃO}

Ponto que não determinou controvérsias nos debates na confecção do Estatuto foi a definição do caráter subsidiário, ou complementar, do Tribunal 
Penal Internacional ${ }^{2}$ (TPI). Estados tendem a ser possessivos quanto ao seu direito de exercer jurisdição criminal de forma que "o TPI é percebido como um risco à soberania. Assim, dos Estados se espera que investiguem e processem para que se barre o TPI de envolver-se ${ }^{3 \prime}$. Por isso, já nas suas primeiras linhas, o Estatuto de Roma reconhece que os países membros têm preferência no julgamento dos autores dos crimes listados na sua competência ${ }^{4}$. De fato, consta no preâmbulo do Estatuto: "sublinhando que o Tribunal Penal Internacional, criado pelo presente Estatuto, será complementar às jurisdições penais nacionais". Da mesma forma, consta no artigo $1 .$. que "é criado, pelo presente instrumento, um Tribunal Penal Internacional ("o Tribunal"). O Tribunal será uma instituição permanente, com jurisdição sobre as pessoas responsáveis pelos crimes de maior gravidade com alcance internacional, de acordo com o presente Estatuto, e será complementar às jurisdições penais nacionais. A competência e o funcionamento do Tribunal reger-se-ão pelo presente Estatuto".

Essa complementaridade tem dois efeitos básicos: tanto reforça a soberania dos Estados, dando-Ihes a primazia para julgamentos dos crimes universais mais graves, quanto assume a condição de vigilante sobre a jurisdição criminal dos Estados, perscrutando a aplicação da lei penal e verificando se a mesma se encontra de acordo com os ditames da justiça. Assim, ao mesmo tempo em que o TPI garante ao Estado o seu direito de julgar, exige que o Estado o faça de forma adequada.

Concomitantemente, reconhece-se que é característica evidente do Direito Internacional Criminal a existência do instituto da anistia. Essa forma de "esquecimento" dos crimes cometidos é utilizada em grande escala pela comunidade internacional e normalmente acompanha as negociações de

\footnotetext{
${ }^{2}$ BOURDON, Willian, La Cour pénale internationale. Paris: Éditions du Seuil, 2000, p. 26.

${ }^{3}$ KLEFFNER, Jann K., Complementarity as a Catalyst for Compliance, in KLEFFNER, Jann K. and KOR, G., (eds.), Complementary Views on Complementarity. Proceedings of the International Roundtable on the Complementary Nature of the International Criminal Court Amsterdam, 25/26 June 2004. The Hague: T.M.C. Asser Press, 2006, p. 79-104, p. 82.

${ }^{4}$ HOLMES, John T., Complementarity: National Courts v. ICC, in CASSESE et al. (ed.), The Rome Statute of International Criminal Court: a commentary. 2 v. Oxford: Oxford University Press, 2002, pp. 667-685, p. 667.

${ }^{5}$ Do Estatuto, no seu preâmbulo.

${ }^{6}$ Do Estatuto, no seu artigo 1.‥
}

Revista Brasileira de Direito Internacional, Curitiba, v.1, n.1, jan./jun.2005 
cessar-fogo e os debates pelo fim de conflitos. Dependendo da forma que assuma, a anistia pode ter um caráter mais ou menos amplo, podendo servir como meio de busca pela verdade e pacificação social ou como mera escusa para evitar o julgamento de responsáveis por crimes universais gravíssimos.

Esses dois institutos parecem, por vezes, entrar em conflito. De fato, diversas dúvidas surgem quando tais elementos são colocados lado a lado. Afinal, é a anistia exercício suficiente de jurisdição para afastar a atuação do TPI? Se sim, que forma a anistia precisa assumir para que possa ser considerada efetiva aplicação de justiça? Ou seriam esses mecanismos absolutamente antitéticos e impossíveis de aproximação, obrigando-se o TPI a acionar a sua complementaridade cada vez que se deparar com uma lei de anistia aplicada como forma de realização de justiça?

O presente texto visa a analisar essa característica elementar do Tribunal Penal Internacional, que é a complementaridade, e sua interação com as anistias. Para tanto, discorre-se, em um primeiro capítulo, sobre a noção de complementaridade, apresentando-se, brevemente, as suas duas formas - a idéia de manutenção da soberania e o efeito de controle do TPI sobre esse exercício soberano - além de uma rápida discussão sobre as situações em que o TPI poderá atuar complementando a jurisdição nacional. Em seguida, o texto, em sua segunda parte, discorre sobre as anistias no Direito Internacional Penal e, em especial, sobre a forma que assumem para, em seguida, discutir quais dessas espécies podem ser aceitas pelo TPI como exercício válido de jurisdição.

Finalmente, o texto termina apresentando a conclusão de que o TPI tem também um compromisso com a paz e a reestruturação social. Na medida em que o exercício da justiça possa comprometer um processo de paz em trâmite em Estados já castigados por longos conflitos nacionais ou internacionais, cabe ao TPI realizar um profundo estudo do caso e lançar sua decisão optando ou pela realização da paz ou da justiça.

Revista Brasileira de Direito Internacional, Curitiba, v.1, n.1, jan./jun.2005 


\section{A DUPLA FUNÇÃO DA COMPLEMENTARIDADE}

\subsection{O PRIMEIRO SENTIDO DA COMPLEMENTARIDADE: A GARANTIA DA SOBERANIA DOS ESTADOS}

O TPI jamais pretendeu tirar a jurisdição original dos Estados para o julgamento de criminosos responsáveis pelos crimes mais graves ${ }^{7}$. Daí o seu caráter de subsidiariedade ou complementaridade, servindo apenas de garantia de que, em casos especialíssimos em que um Estado não possa ou não queira reprimir aqueles crimes mais graves contra a humanidade, tais condutas não passarão impunes e o TPI entrará em cena.

Assim, é premissa maior do Tribunal a sua complementaridade e a idéia de que "as jurisdições criminais nacionais tem a responsabilidade primária na repressão dos crimes [do Estatuto de Roma]". SCHABAS aponta que "de fato, o Estatuto deixa aos sistemas de justiça nacionais a primeira chance de julgar os presumidamente criminosos e é somente quando os mecanismos de justiça interna não são deflagrados que o Tribunal criminal internacional pode exercer a sua jurisdição"."

Com tais disposições, a Convenção de Roma pretendeu reforçar tanto a manutenção da soberania dos países signatários quanto a idéia de que a ordem internacional, na instituição TPI, "não deve intervir desde que as jurisdições internas exerçam suas competências ${ }^{10 ",}$ com capacidade e interesse em aplicar a justiça ao caso concreto. Segundo SCHABAS ${ }^{11}$, o TPI

\footnotetext{
7 CRYER, Robert, "Sudan, Resolution 1593, and International Criminal Justice", in Leiden Journal of International Law (2006), n. 19, p. 201.

${ }^{8}$ KLEFFNER, Jann K. op. cit, p. 80.

9 "en effet, le Statut laisse aux systèmes de justice nationaux la première chance de juger les criminels présumés et, c'est seulement lorsque les mécanismes de justice interne ne sont pas éclenchés que la Cour criminelle internationale peut exercer sa jurisdiction". SCHABAS, William, La Cour criminelle internationale: un pas de plus contre l'impunité, em Proceedings $27^{\text {th }}$. Annual Conference October, 15-17, 1998, Canadian Council of International Law, The Impact of International Law on the Practice of Law in Canada, Hague: Kluwer Law International, 1999 , p. 5.

10 " $n$ 'est pas fondée à intervenir dès lors que les jurisdictions internes exercent leurs compétences". SUR, Serge, Ver une Cour Penale internationale: la Convention de Rome entre les ONG et le Conseil de Securite, em Révue Général de Droit International Public, 1999-2, p. 42.

${ }^{11}$ SCHABAS, William, op. cit., p. 5-6.
}

Revista Brasileira de Direito Internacional, Curitiba, v.1, n.1, jan./jun.2005 
poderá exercer sua jurisdição quando faltar coragem ao país para julgar os criminosos, pois eles estão em posições políticas de autoridade; quando o sistema de justiça de um Estado não for mais funcional; quando o Estado toma medidas para tornar o processo ineficaz com 0 fim de afastar a responsabilidade criminal do acusado; quando o processo não tiver sido realizado de maneira independente ou imparcial, em desrespeito àquelas garantias básicas reconhecidas e protegidas pelo direito internacional e quando "vistas as circunstâncias, o processo não foi realizado de forma a fazer justiça ao presumido criminoso ${ }^{12,}$.

Assim fazendo, o TPI diferenciou-se dos tribunais internacionais predecessores: os Tribunais Militares Internacionais da Segunda Guerra Mundial de Nuremberg e Tóquio, o Tribunal Penal Internacional para a Antiga lugoslávia e o Tribunal Penal Internacional para Ruanda. Nessas instituições, os Tribunais internacionais tinham preferência, sobrepondo-se aos órgãos jurisdicionais pré-existentes, e determinando a justiça independentemente da vontade dos países sobre os quais tinham aplicabilidade ${ }^{13}$. Mais do que isso, podiam inclusive tomar para si processos já em curso na jurisdição original, atuando com onipotência sobre a justiça local ${ }^{14}$. Nesses casos, a prioridade concedida aos tribunais internacionais é explicada porque "o Conselho de

\footnotetext{
12 “...vu les cirsconstances, le procès n'a pas été mené de façon à traduire en justice le présumé criminel'. Idem, p. 6.

${ }_{13}$ Veja-se o que diz o artigo $9^{\circ}$, do Estatuto do Tribunal Penal Internacional para a ExYugoslávia, criado pela Resolução 827 de 1993, do Conselho de Segurança das Nações Unidas: "Article 9. Concurrent jurisdiction. 1. The International Tribunal and national courts shall have concurrent jurisdiction to prosecute persons for serious violations of international humanitarian law committed in the territory of the former Yugoslavia since 1 January 1991. 2. The International Tribunal shall have primacy over national courts. At any stage of the procedure, the International Tribunal may formally request national courts to defer to the competence of the International Tribunal in accordance with the present Statute and the Rules of Procedure and Evidence of the International Tribunal'. Assim também o artigo 8. do Estatuto do Tribunal Penal Internacional para a Ruanda: "Article 8. Compétences concurrentes.1. Le Tribunal international pour le Rwanda et les juridictions nationales sont concurremment compétents pour juger les personnes présumées responsables de violations graves du droit international humanitaire commises sur le territoire du Rwanda et les citoyens rwandais présumés responsables de telles violations commises sur le territoire d'États voisins entre le 1er janvier et le 31 décembre 1994. 2. Le Tribunal international pour le Rwanda a la primauté sur les juridictions nationales de tous les États. À tout stade de la procédure, il peut demander officiellement aux juridictions nationales de se dessaisir en sa faveur conformément au présent statut et à son règlement de procédure et de preuve". As fontes, visitadas em 15 de julho de 2006, são: http://www.un.org/icty/legaldoc-e/index.htm e http://69.94.11.53/FRENCH/basicdocs/statute_f.html.

${ }^{14}$ HOLMES, John T. op. cit., p. 669.
}

Revista Brasileira de Direito Internacional, Curitiba, v.1, n.1, jan./jun.2005 
Segurança enfrentava situações nas quais, na antiga lugoslávia havia uma falta de interesse em investigar e processar efetivamente aqueles responsáveis por crimes internacionais, e na Ruanda havia falta de condições para tanto ${ }^{15 "}$.

Todavia, tratava-se de situações extraordinárias e especialíssimas, daí a primazia dos órgãos internacionais. No caso do TPI, a condição é inversa: por ser um órgão que se pretende amplo, intenta funcionar apenas como instância subsidiária, garantindo aos Estados a manutenção da soberania pela aplicação da justiça criminal.

\subsection{O SEGUNDO SENTIDO DA COMPLEMENTARIDADE: O TPI COMO INSTÂNCIA DE CONTROLE}

Um segundo aspecto da complementaridade, e um dos mais importantes objetivos pretendidos com a criação do TPI, é o fato de que os Estados, ao se tornarem signatários do Estatuto, assumem a obrigação de efetivamente julgar e punir os acusados das práticas dos crimes da competência do Tribunal - daí constar no preâmbulo: "relembrando que é do dever de cada Estado submeter à sua jurisdição criminal os responsáveis por crimes internacionais $^{16 " .}$. Assim a complementaridade não é apenas uma representação da soberania do Estado, e uma limitação ao exercício da jurisdição pela esfera internacional, mas representa também "um princípio que vem reforçar a existência de uma obrigação estatal não formal (...) de perseguir, no plano nacional, as violações do direito humanitário ${ }^{17}$." O TPI, portanto, funciona como um "catalisador ${ }^{18 "}$ para que as jurisdições nacionais atuem reprimindo crimes universais.

Assim, o Tribunal é subsidiário e dá preferência efetiva para que o Estado membro aplique o Direito, julgando os acusados de acordo com as suas

\footnotetext{
${ }^{15}$ Ibid.

${ }^{16}$ Do Estatuto, no seu preâmbulo: "Rappelant qu'il est du devoir de chaque État de soumettre à sa juridiction criminelle les responsables de crimes internationaux".

17 "un principe qui vient sougligner l'existence d'une obligation étatique non formelle (...) de poursuivre, sur le plan national, les violations du droit humanitaire", POLITI, Mauro, "Le Statut de Rome de la Cour Pénale Internationale: le point de vue d'un négociateur", em Révue General de Droit Internationale Public (1999), n. 4, p. 843.

${ }^{18}$ KLEFFNER, Jann K., op. cit., p. 79.
}

Revista Brasileira de Direito Internacional, Curitiba, v.1, n.1, jan./jun.2005 
regras. Todavia, quando o Tribunal reconhecer nessa aplicação do direito uma intenção de fazer fugir o acusado à aplicação da lei, seja pela condução deliberada do processo nesse sentido ou pela "demora injustificada", com vistas à prescrição, o Tribunal pode ter sua jurisdição acionada, com o fim de substituir a jurisdição nacional, garantindo a aplicação da lei ao caso concreto.

Por isso a complementaridade não deve ser entendida apenas como uma instância a ser usada para casos em que o país não possa aplicar o direito (por destruição de todo o sistema legal, como em caso de guerra, por exemplo). Mas também como instância em paralelo, que pode competir com a instância original, com o fim de garantir que os crimes sejam punidos.

Aqui, DELMAS-MARTY menciona que "...o princípio da complementaridade colocado pela Convenção de Roma deveria sem dúvida ser interpretado como uma verdadeira complementaridade - o que quer dizer que as esferas de competência seriam diferentes e não concorrentes -, e não como uma subsidiariedade de fato em nome da qual resignar-se-ia a descartar a competência do TPI por simples razões diplomáticas ${ }^{19,}$.

Significa dizer que a partir da assinatura e ratificação do Estatuto, os Estados se comprometem com toda a coletividade internacional a reprimir as espécies criminais em questão. Se o fizerem não precisarão, regra geral, portanto, aceder ao TPI - daí a complementaridade. E nesse "direito-dever" de aplicar a justiça criminal serão fiscalizados pelo Tribunal, já que se não aplicarem o direito de forma adequada, imparcial e descomprometida na investigação, processamento e punição dos crimes referidos, caberá, aí sim, a jurisdição da Corte. Isso vai evitar, por certo, que a lei seja aplicada de maneira frouxa, com vistas unicamente à absolvição do acusado, que eventualmente possa ter poder político para tanto. De certa forma, é uma espécie de "domesticação vertical"20" do sistema, como apontou KLEFFNER.

\footnotetext{
19 "...le principe de complémentarité posé par la Convention de Rome devrait sans doute être interprété comme une véritable complémentarité - de que veut dire que les sphères de compétente seraient diferentes et non concurrentes -, et non comme une subsidiarité de fait au nom de laquelle on se résignerait à écarter la compétence de la CPI pour de simples raisons diplomatiques", DELMAS-MARTY, Mireille, "La responsabilité pénale en échec (prescription, amnistie, immunités)", em CASSESE, Antonio e DELMAS-MARTY, Mireille, "Jurisdictions nationales et crimes internationaux", Paris: PUF, 2002, p. 653.

${ }^{20}$ KLEFFNER, Jann K., op. cit., p. 81.
}

Revista Brasileira de Direito Internacional, Curitiba, v.1, n.1, jan./jun.2005 
Não é necessário ter muita imaginação para vislumbrar possibilidades de fugas lícitas ou quase lícitas à responsabilização criminal de poderosos. Aliás, assistimos a vários desses casos na América Latina e a muitos deles dentro do nosso próprio Estado, ainda que nem sempre nos crimes de genocídio, de lesa-humanidade e de guerra. Por exemplo, as leis de anistia argentinas, recentemente revogadas pelo Congresso platino ${ }^{21}$, que serviram apenas a proteger os grandes criminosos pelos crimes que cometeram durante os anos da ditadura militar. Salta aos olhos, também, o caso Pinochet ${ }^{22}$, que demonstra à evidência a falta de vontade política em julgar um dirigente pelos crimes que the são imputados. Ao que parece, a decisão inglesa de devolvê-lo ao Chile fará com que a punição do general acabe tendo que ficar, cedo ou tarde, a encargo do Todo-poderoso, já que as instâncias terrenas, apesar do clamor popular, se recusam a submetê-lo ao processo jurisdicional que tanto merece.

E o caso brasileiro? Não se pode dizer que seja o Brasil o melhor país para criticar a realidade acima apresentada. Mesmo que não tenhamos 0 mesmo histórico de nossos vizinhos ${ }^{23}$, ainda estamos sujeitos a uma série de

${ }^{21}$ Conforme amplamente divulgado pela mídia, as leis de anistia argentinas, concedidas em benefício dos militares acusados do cometimento de crimes durante a ditadura militar no país, de 1976 a 1983, foram revogadas pelo Congresso argentino, abrindo as portas à punição daqueles criminosos, seja pelos tribunais platinos ou por jurisdições internacionais, já que há diversos pedidos de extradição feitos à Justiça argentina. Conforme notícia publicada no sítio da BBC Brasil, visitado em 08/07/06, verificável em http://www.bbc.co.uk/portuguese/noticias/story/2003/08/030821 argentinacg.shtml.

${ }^{22}$ Exatamente 28 anos antes do atentado terrorista às torres gêmeas do World Trade Center, em 11 de setembro de 1973, o general Augusto Pinochet, com um golpe militar violento, depôs o presidente socialista eleito Salvador Allende, e se proclamou presidente do Chile. $O$ sangrento golpe militar matou mais de 3.000 pessoas e deu início a um reino de terror, com tortura de dezenas de milhares de pessoas e provocou o exílio de mais de 250.000 chilenos. Foram desmanteladas antigas instituições democráticas, privatizada a economia e extintos os partidos políticos. A ditadura militar imposta ao Chile pelo General Pinochet perdurou 17 anos, até 1990, quando o velho militar deixou o governo, mas se fez senador vitalício do Chile. A violência imposta por Pinochet e os seus órgãos de repressão, DINA e CNI, alarmaram o mundo civilizado, uma vez que o violento regime promoveu um autêntico genocídio político de cidadãos chilenos e outros, em pleno final do século XX. Daí a decisão da Justiça Espanhola, já tocada pelos ares moralizadores do TPI e pelo esforço do seu magistrado Baltazar Garzón, em julgar o genocida por crimes contra humanidade e, especialmente, contra cidadãos espanhóis. O velho general foi preso na Inglaterra, quando se recuperava de uma intervenção cirúrgica, mas a corte da ilha, depois de várias reuniões, liberou o preso, por questões humanitárias enviando-o ao seu país de origem. Como se imagina, o Chile nunca julgará o déspota.

${ }^{23}$ Interessante a colocação do economista e ex-candidato à presidência da República, José Serra, publicada na revista Veja, ano $36, n . .37$, de 17 de setembro de 2003 , comparando 0

Revista Brasileira de Direito Internacional, Curitiba, v.1, n.1, jan./jun.2005 
mazelas que corrompem o nosso sistema. São o corporativismo e a corrupção que parecem imiscuídos em todos os planos da administração nacional (qualquer jornal aponta, diariamente, uma série de escândalos de relevo) que impedem, muitas vezes, a aplicação da lei. Isso desde o "esquecimento" ou "arquivamento" de inquéritos por alguns Delegados de Polícia (absolutamente ilícitos) até a manutenção por votações perfeitamente defensáveis do ponto de vista jurídico (e, pasme-se, lícitas e legítimas!) das imunidades parlamentares de políticos que mereciam indubitavelmente ao menos um processo judicial para a verificação de suas alegadas inocências.

\subsection{QUANDO O TPI PODE ATUAR?}

Foi por isso que o Estatuto se antecipou e determinou a possibilidade de atuar nesses casos, absorvendo a competência e tomando para si a jurisdição quando houver ocorrências dessas espécies. O TPI é também um sistema de "vigilância jurisdicional". Assim, as determinações do artigo 17 do Estatuto merecem análise.

$\mathrm{O}$ artigo $17^{24}$ inicia mencionando as "questões de admissibilidade" e,

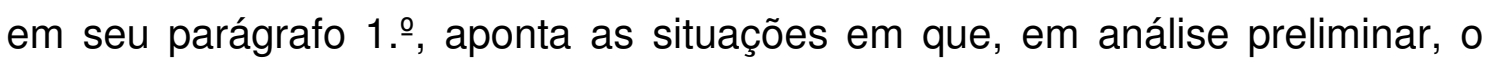
Tribunal decidirá pela inadmissibilidade de um caso que the seja apresentado. São quatro: quando o caso já estiver sendo investigado ou processado em Estado com jurisdição para tanto, a menos que este Estado não seja capaz ou não esteja disposto a fazê-lo; quando o caso já tiver sido investigado por um

golpe militar brasileiro de 1964 com aquele realizado contra Allende, em 1973: "comparando àquele banquete de felinos disputando suas presas, o golpe de 1. de abril de 1964 no Brasil parecia um delicado chá de senhoras".

${ }^{24}$ Do Estatuto, no seu artigo 17: "Artigo 17. Questões Relativas à Admissibilidade. 1.Tendo em consideração o décimo parágrafo do preâmbulo e o artigo 1, o Tribunal decidirá sobre a não admissibilidade de um caso se: a) $O$ caso for objeto de inquérito ou de procedimento criminal por parte de um Estado que tenha jurisdição sobre o mesmo, salvo se este não tiver vontade de levar a cabo o inquérito ou o procedimento ou não tenha capacidade para o fazer; b) $O$ caso tiver sido objeto de inquérito por um Estado com jurisdição sobre ele e tal Estado tenha decidido não dar seguimento ao procedimento criminal contra a pessoa em causa, a menos que esta decisão resulte do fato de esse Estado não ter vontade de proceder criminalmente ou da sua incapacidade real para o fazer; c) A pessoa em causa já tiver sido julgada pela conduta a que se refere a denúncia, e não puder ser julgada pelo Tribunal em virtude do disposto no parágrafo $3^{\circ}$ do artigo 20; d) 0 caso não for suficientemente grave para justificar a ulterior intervenção do Tribunal."

Revista Brasileira de Direito Internacional, Curitiba, v.1, n.1, jan./jun.2005 
Estado com jurisdição para tanto e este Estado tenha entendido descabida a ação penal, salvo se essa decisão advém da falta de interesse ou incapacidade para a propositura da dita ação; quando o indivíduo já tiver sido processado pelo crime denunciado e o Tribunal não puder fazê-lo segundo as regras do "ne bis in idem"; quando o caso não for suficientemente grave para justificar a adoção de outras medidas por parte do Tribunal.

No parágrafo $2 .$. , o artigo $17^{25}$ menciona os casos em que o Tribunal pode atuar nas exceções, ou seja, determinando quando há ou não "disposição de agir" ou, mais literalmente "falta de vontade do Estado" de aplicar a lei. $\mathrm{Na}$ letra "a", aponta-se o caso em que o processo tenha sido ou esteja sendo conduzido, ou já tenha sido sentenciado, com o único fim de subtrair o acusado da sua responsabilidade criminal; na letra "b", quando houver um atraso injustificado no processo que seja incompatível com intenção de submeter o indivíduo à ação da justiça; e "c", quando a condução do processo não estiver sendo ou não tenha sido feita de forma independente ou imparcial, ou de forma incompatível com a realização da justiça. Essa é uma decisão a ser tomada pelo próprio TPI em cada caso concreto sendo ele, portanto, "árbitro de sua própria jurisdição ${ }^{26 " . ~}$

A Câmara de Instrução verificará se o país em questão está em condições de garantir a presença do acusado durante os trabalhos e de amealhar as provas e elementos necessários à boa condução do processo criminal $^{27}$. Também é necessário verificar se o Estado tem legislação específica para aplicar no caso, dando conta da seriedade da situação, já que a ausência

\footnotetext{
${ }^{25}$ Do Estatuto, no seu artigo 17, parágrafo 2...: "2. A fim de determinar se há ou não vontade de agir num determinado caso, o Tribunal, tendo em consideração as garantias de um processo eqüitativo reconhecidas pelo direito internacional, verificará a existência de uma ou mais das seguintes circunstâncias: a) O processo ter sido instaurado ou estar pendente ou a decisão ter sido proferida no Estado com o propósito de subtrair a pessoa em causa à sua responsabilidade criminal por crimes da competência do Tribunal, nos termos do disposto no artigo 5o; b) Ter havido demora injustificada no processamento, a qual, dadas as circunstâncias, se mostra incompatível com a intenção de fazer responder a pessoa em causa perante a justiça; c) O processo não ter sido ou não estar sendo conduzido de maneira independente ou imparcial, e ter estado ou estar sendo conduzido de uma maneira que, dadas as circunstâncias, seja incompatível com a intenção de levar a pessoa em causa perante a justiça,".

${ }^{26}$ HOLMES, John T., op. cit., p. 672.

${ }^{27}$ HOLMES, John T., op. cit., p. 678.
}

Revista Brasileira de Direito Internacional, Curitiba, v.1, n.1, jan./jun.2005 
de legislação material pode efetivamente se transformar em um entrave à persecução criminal ${ }^{28}$.

A Câmara de Instrução também irá verificar se o Estado pretende "genuinamente" levar adiante o processo com base nos princípios de equidade e justiça, dando conta das condenações que se fizerem necessárias. Evidentemente, essa verificação - pelo caráter subjetivo que carrega - é extremamente complexa, mas ainda assim é perfeitamente viável. Se o TPI perceber que os procedimentos criminais estão sendo desenvolvidos com 0 objetivo de proteger os acusados de uma eventual condenação (artigo 17, 2, letra "a"), com uma demora injustificada (mesmo dispositivo, letra "b") ou de uma forma não independente ou imparcial (letra "c"), então a Câmara deverá declarar o caso como admissível e dar início ao processo.

Assim, ao mesmo tempo em que o TPI dá ao Estado signatário o direito de aplicar jurisdição nos casos de crimes universais, dando, portanto, força à soberania de seus Estados componentes, também funciona como verificador da legalidade desse exercício jurisdicional, garantindo a aplicação da justiça. Através de regras de interação entre a Corte e as jurisdições nacionais e da incitação ao exercício da jurisdição nacional, a complementaridade se dá na sua total extensão e assim pretende cumprir com a promessa de evitar as mais graves violações aos bem jurídicos mais importantes da humanidade.

\footnotetext{
${ }^{28}$ KLEFFNER, Jann K., The Impact of Complementarity on National Implementation of Substantive International Criminal Law, in Journal of International Criminal Justice (Abril de 2003), n. 1, pp. 86-113, p. 88.
}

Revista Brasileira de Direito Internacional, Curitiba, v.1, n.1, jan./jun.2005 


\section{ANISTIAS E O TPI}

Como se sabe, a resposta do Estado ao cometimento de um crime pode assumir diversas formas. Desde uma sentença condenatória até o reconhecimento de uma prescrição, uma transação criminal, uma negociação através do "plea bargaining" ou a concessão de uma anistia. Na esfera nacional, todas essas espécies são admitidas e bem-vindas de acordo com a configuração dos fatos, a espécie criminal a que se aplicam, a situação política, a intenção de apaziguar os ânimos sociais, etc. Embora os Estados estejam livres para exercer a sua soberania através da jurisdição criminal da forma que bem entenderem, há certos parâmetros entendidos como mais adequados pela comunidade internacional e que precisam ser alcançados para que se admita ocorrente um nível mínimo de justiça.

O caso mais complicado é sem dúvida o da anistia. Anistias (termo de origem grega significando "esquecimento") são "um ato de poder soberano que imuniza pessoas contra persecuções criminais por crimes cometidos" ${ }^{29 "}$. Esse "esquecimento" por vezes é manifestação de interesses escusos no sentido de permitir aos criminosos a fuga à aplicação da justiça. Afinal, qual é o limite entre essas práticas e a "genuína" justiça no caso concreto para o TPI? Quando será a anistia uma efetiva manifestação de soberania e quando deverá ser condenada como uma forma de permitir que os criminosos escapem à punição? E, afinal, pode efetivamente o TPI requerer a realização da justiça em detrimento da paz?

Essas são questões de alta complexidade que vêm provocando profundos debates na esfera internacional, especialmente porque o Estatuto de Roma parece não ter resolvido adequadamente a questão ${ }^{30}$ - ou mesmo parece ter silenciado totalmente sobre o tema ${ }^{31}$. Na medida em que, segundo SCHARF, citando SCHEFFER "anistias estão sempre na mesa em

\footnotetext{
${ }^{29}$ SCHARF, Michael P., The Amnesty Exception to the Jurisdiction of the International Criminal Court, in Cornell International Law Journal (1999), n. 32, pp. 507-527, p. 507-508.

${ }^{30}$ Idem, p. 521.

${ }^{31}$ DUGARD, John, Possible Conflicts of Jurisdictions with Truth Commissions, em CASSESE et al. (ed.), The Rome Statute of International Criminal Court: a commentary. 2 v. Oxford: Oxford University Press, 2002, pp. 693-704, p. 700.
}

Revista Brasileira de Direito Internacional, Curitiba, v.1, n.1, jan./jun.2005 
negociações de paz ${ }^{32 ", ~ e ́ ~ i m p r e s c i n d i ́ v e l ~ q u e ~ s e ~ l a n c e m ~ a l g u m a s ~ l u z e s ~ s o b r e ~}$ essa questão.

\subsection{ANISTIAS NO DIREITO INTERNACIONAL PENAL}

Ainda que a concessão de anistias não seja a forma mais comum de realização de justiça, ela tem sido uma experiência razoavelmente comum na história recente do Direito Internacional Penal, especialmente através das chamadas Comissões de Verdade e Reconciliação ${ }^{33}$ (CVR). A bem da verdade essa espécie tem sido, junto com os tribunais internacionais criminais, uma das formas encontradas pela comunidade internacional para lidar com as violações sistemáticas e em larga escala de direitos humanos ${ }^{34}$. Dentre as ocorrências, as mais lembradas são aquela que teve seus efeitos na África do Sul - após a era de apartheid - e as que concederam anistias aos crimes cometidos durante a era de ditaduras militares na América Latina (especialmente Chile, Argentina, El Salvador e Guatemala) ${ }^{35}$.

Segundo HAYNER, "é em parte devido ao alcance limitado dos tribunais, e parte devido ao reconhecimento de que nem mesmo os processos criminais bem sucedidos não resolvem os conflitos e a dor associada aos abusos do passado que as autoridades transnacionais têm cada vez mais se dedicado à busca pela verdade como componente central na sua estratégia de responder às atrocidades do passado ${ }^{36 " .}$. Em muitos casos de conflito internacional, a opção pela punição jurisdicional dos culpados não é reconhecida como a melhor forma de pacificação da sociedade. Ainda que desejada, essa punição é normalmente seguida da manutenção da instabilidade social e, por vezes, continuidade da guerra e do sofrimento da população. Sabedores que o fim do conflito Ihes trará a certa condenação pelas autoridades internacionais, é comum que os senhores da guerra prolonguem

\footnotetext{
${ }^{32}$ SCHARF, Michael P., op. cit., p. 525.

33 "Truth and Reconciliation Commissions".

${ }^{34}$ DUGARD, John, op. cit., p. 693.

${ }^{35}$ DUGARD, John, op. cit., p. 694.

36 HAYNER, Priscilla B., Unspeakable Truths: confronting state terror and atrocity. London: Routledge, 2001, p.14.
}

Revista Brasileira de Direito Internacional, Curitiba, v.1, n.1, jan./jun.2005 
os conflitos tanto quanto possível e continuem cometendo os atos pelos quais deveriam ser processados. Isso parece ser especialmente verdade em determinadas situações, especialmente porque "em países em que os militares mantém um controle substancial mesmo depois de deixarem o poder, esforços para processar as violações cometidas podem provocar rebeliões 37". Assim, por vezes o interesse da população é, de fato, esquecer a guerra e os crimes cometidos para conseguir, em troca, a paz e a chance de reconstruir o seu arrasado país ${ }^{38}$. O esquecimento forçado das desgraças da guerra pode

${ }^{37}$ ORENTLICHER, Diane, "Settling Accounts: the Duty to Prosecute Human Rights Violations of a Prior Regime", in Yale Law Journal (June 1991), n. 100, pp. 2537-2615, p. 2545.

${ }_{38}$ Aqui, vale a menção ao caso sul-africano, citando-se a decisão da Corte Constitucional SulAfricana sobre a anistia concedida aos crimes cometidos naquele país: "Every decent human being must feel grave discomfort in living with a consequence which might allow the perpetrators of evil acts to walk the streets of this land with impunity, protected in their freedom by an amnesty immune from constitutional attack, but the circumstances in support of this course require carefully to be appreciated. Most of the acts of brutality and torture which have taken place have occurred during an era in which neither the laws which permitted the incarceration of persons or the investigation of crimes, nor the methods and the culture which informed such investigations, were easily open to public investigation, verification and correction. Much of what transpired in this shameful period is shrouded in secrecy and not easily capable of objective demonstration and proof. Loved ones have disappeared, sometimes mysteriously and most of them no longer survive to tell their tales. Others have had their freedom invaded, their dignity assaulted or their reputations tarnished by grossly unfair imputations hurled in the fire and the cross-fire of a deep and wounding conflict. The wicked and the innocent have often both been victims. Secrecy and authoritarianism have concealed the truth in little crevices of obscurity in our history. Records are not easily accessible, witnesses are often unknown, dead, unavailable or unwilling. All that often effectively remains is the truth of wounded memories of loved ones sharing instinctive suspicions, deep and traumatising to the survivors but otherwise incapable of translating themselves into objective and corroborative evidence which could survive the rigours of the law. The Act seeks to address this massive problem by encouraging these survivors and the dependants of the tortured and the wounded, the maimed and the dead to unburden their grief publicly, to receive the collective recognition of a new nation that they were wronged, and crucially, to help them to discover what did in truth happen to their loved ones, where and under what circumstances it did happen, and who was responsible. That truth, which the victims of repression seek so desperately to know is, in the circumstances, much more likely to be forthcoming if those responsible for such monstrous misdeeds are encouraged to disclose the whole truth with the incentive that they will not receive the punishment which they undoubtedly deserve if they do. Without that incentive there is nothing to encourage such persons to make the disclosures and to reveal the truth which persons in the positions of the applicants so desperately desire. With that incentive, what might unfold are objectives fundamental to the ethos of a new constitutional order. The families of those unlawfully tortured, maimed or traumatised become more empowered to discover the truth, the perpetrators become exposed to opportunities to obtain relief from the burden of a guilt or an anxiety they might be living with for many long years, the country begins the long and necessary process of healing the wounds of the past, transforming anger and grief into a mature understanding and creating the emotional and structural climate essential for the "reconciliation and reconstruction" which informs the very difficult and sometimes painful objectives of the amnesty articulated in the epilogue The alternative to the grant of immunity from criminal prosecution of offenders is to keep intact the abstract right to such a prosecution for particular persons without the evidence to sustain the prosecution successfully, to continue to keep the

Revista Brasileira de Direito Internacional, Curitiba, v.1, n.1, jan./jun.2005 
parecer um preço razoável a pagar pela conquista da paz. Em um cenário como esse, a atuação de um Tribunal Internacional Criminal pode ser desastrosa. Por isso a alternativa proposta é normalmente o estabelecimento das CVR ou a concessão da anistia simples.

Sem uma forma, mandato ou composição específica, as CVR pretendem a pacificação social através da verdade ${ }^{39}$. Na sua forma mais comum, oferecem anistia dos crimes praticados em troca de que os acusados informem à comissão a verdade dos seus atos. Isso abre caminho para a concessão de indenizações e dá aos familiares das vítimas a possibilidade de conhecer o destino de seus entes queridos. Privilegia-se, dessa forma, a reconciliação social em lugar da retribuição pelos crimes cometidos ${ }^{40}$. Assim, a verdade sobre crimes como o "desaparecimento" - que são extremamente difíceis de serem solucionados - acaba trazida à tona e, ainda que de uma forma dolorosa, acabam por acalmar os ânimos da sociedade. Segundo alguns autores, a anistia não pode ser confundida com impunidade: "aonde as anistias foram negociadas pela paz, os governos envolvidos têm reparado monetariamente as vítimas e seus familiares, estabelecido comissões de verdade para documentar os abusos (e, às vezes, identificar os perpetradores pelo nome), e instituído banimentos e exclusões (...) que mantém os criminosos longe de posições que demandam confiança pública ${ }^{41 "}$.

O caso mais celebrado dessa espécie é o da África do Sul. Essa CVR determinou a concessão de anistias a partir de um processo amplo e

dependants of such victims in many cases substantially ignorant about what precisely happened to their loved ones, to leave their yearning for the truth effectively unassuaged, to perpetuate their legitimate sense of resentment and grief and correspondingly to allow the culprits of such deeds to remain perhaps physically free but inhibited in their capacity to become active, full and creative members of the new order by a menacing combination of confused fear, guilt, uncertainty and sometimes even trepidation. Both the victims and the culprits who walk on the "historic bridge" described by the epilogue will hobble more than walk to the future with heavy and dragged steps delaying and impeding a rapid and enthusiastic transition to the new society at the end of the bridge, which is the vision which informs the epilogue". The Azanian Peoples Organization (AZAPO) versus the President of the Republic of South Africa, Decisão da Corte Constitucional da África do Sul, caso CCT17/96, decisão em 25 de julho de 1996, p. 17-19, disponível em http://www.constitutionalcourt.org.za/Archimages/2529.PDF, visitado em 15 de julho de 2006.

${ }^{39}$ DUGARD, John, op. cit., p. 694.

40 DUGARD, John, Dealing With Crimes of a Past Regime. Is Amnesty Still an Option?, in Leiden Journal of International Law (1999), n. 12, pp. 1001-1015, p. 1005.

${ }^{41}$ SCHARF, Michael P., op. cit., p. 512.

Revista Brasileira de Direito Internacional, Curitiba, v.1, n.1, jan./jun.2005 
independente de investigação irrestrita da verdade, com a nominação de acusados e com alcance não apenas de mortes, mas de toda espécie de violação de direitos humanos (como tortura, por exemplo). A anistia somente seria concedida àqueles que pessoalmente pleiteassem pela mesma e que efetivamente relatassem todos os fatos referentes aos crimes cometidos durante o regime de apartheid de que tinham conhecimento. Aponta-se que 0 resultado desse processo permitiu o fim das tensões e o afastamento do risco de guerra civil ${ }^{42}$.

Obviamente, o caminho mais sábio a se seguir, entre o procedimento jurisdicional e as CVR, é matéria de debate ${ }^{43}$. Há os que prezam a paz em detrimento da justiça e outros que acolhem a opção inversa. Todavia, não existe ainda a medida de equilíbrio entre a necessidade de aplicação de justiça e os riscos de manutenção de um regime militar ou situação similar ${ }^{44}$. De qualquer forma, as CVR são uma realidade pujante na prática do Direito Internacional Criminal, e não podem ser ignoradas como opção válida. Ademais, as CVR não são opostas à persecução criminal e podem, muitas vezes, andar lado a lado com a responsabilização e a punição de criminosos perpetradores dos crimes mais graves ${ }^{45}$ - dependendo apenas da configuração que venham a adotar.

Diferentemente, no caso das anistias diretas, o processo é mais simples. Uma lei lançada já ao fim do regime responsabilizado pelos crimes cometidos determina a simples anistia de todos os possíveis atos criminosos. Assumindo geralmente forma mais ampla possível, costuma liberar tanto os originais opressores quanto os antigos oprimidos, garantindo, assim, um relativo apoio popular. O clássico exemplo é o das anistias concedidas na América Latina com o fim dos regimes militares, especialmente a chilena por conta da exposição do caso Pinochet.

\footnotetext{
${ }^{42}$ SCHARF, Michael P., op. cit., p. 510.

43 DUGARD, John, op. cit., p. 1001.

${ }^{44}$ ORENTLICHER, Diane, op. cit., p. 2539.

${ }^{45}$ DUGARD, John, Possible Conflicts of Jurisdictions with Truth Commissions, em CASSESE et al. (ed.), The Rome Statute of International Criminal Court: a commentary. 2 v. Oxford: Oxford University Press, 2002, pp. 693-704, p. 694.
}

Revista Brasileira de Direito Internacional, Curitiba, v.1, n.1, jan./jun.2005 
É bem verdade que existe uma obrigação internacional direcionada aos Estados de processar e julgar os responsáveis por certas espécies criminosas (normalmente, aqueles crimes reconhecidos como crimes universais), bem como a proibição da concessão de certas anistias. Essa determinação pode ser encontrada em diversas fontes: a Convenção para a Prevenção e Repressão do Crime de Genocídio, no seu artigo $4^{\circ}$., expressamente determina que as pessoas responsáveis pelos ditos crimes "serão punidas"; as Convenções de Genebra de 1949 também fazem expressa a obrigação de processar ou julgar ("aut dedere aut judicare") e não permitem a concessão de anistia nesses $\operatorname{casos}^{46}$; os estatutos dos tribunais internacionais para a ex-lugoslávia e para a Ruanda também seguem o mesmo rumo, deixando clara a impossibilidade de concessão de anistia aos crimes de sua competência; cortes internacionais também adotam essa idéia, assim como, por exemplo, a Corte Interamericana de Direitos Humanos ${ }^{47}$, que assim já julgou tanto em casos como Velásquez Rodriguez ${ }^{48}$, quanto quando apontou as leis de anistias de vários países latinoamericanos como incompatíveis com a Convenção Americana de Direitos do Homem $^{49}$; o Tribunal para a ex-lugoslávia já assim decidiu, referindo-se à prática da tortura no caso Prosecutor v. Furundzija ${ }^{50}$. Esses são apenas alguns dos exemplos lembrados por DUGARD ${ }^{51}$ e por SCHARF ${ }^{52}$.

Todavia, essa não parece ser a prática corrente na esfera internacional. Tanto as CVR quanto as anistias têm sido adotadas constantemente e têm sido endossadas inclusive por organismos internacionais, tais quais as Nações Unidas, como forma adequada de trato

\footnotetext{
${ }^{46}$ SCHARF, Michael P., op. cit., p. 516.

47 Conforme mencionado por ORENTLICHER, a Convenção Inter-Americana têm sido interpretada no sentido de determinar que os Estados membros investiguem e punam todas as sérias violações cometidas contra a integridade física. Veja-se ORENTLICHER, Diane, op. cit., p. 2577,

48 Velasquez Rodriguez Case, Judgment of July 29, 1988, Inter-American Court of Human Rights (Ser. C) No. 4 (1988). Disponível em http://www1.umn.edu/humanrts/iachr/b 11 12d.htm. Acesso em 8 de julho de 2006.

A9 A título de exemplo, ver Corte Inter-Americana de Direitos do Homem, Reports $n^{\circ}$. 29/92 (Uruguai) OEA/L/V/11.82. Doc. 25(1992); e Report n. 24/92 (Argentina), Doc. 24 (1992).

${ }^{50}$ Prosecutor versus Furundzija, Tribunal Criminal Internacional para a ex-lugoslávia, Câmara de Julgamento, caso IT-95-17/1-T (decisão de 10 de Dezembro de 1998), 39 ILM (1999) 317, especialmente o parágrafo 155.

${ }^{51}$ DUGARD, John, op. cit. p. 696-697.

${ }^{52}$ SCHARF, Michael P., op. cit., p. 515-521.
}

Revista Brasileira de Direito Internacional, Curitiba, v.1, n.1, jan./jun.2005 
dos problemas a que se aplicam ${ }^{53}$. Cortes nacionais também seguem a mesma tendência, como no caso da Corte inglesa no caso Pinochet ${ }^{54}$. E a prática internacional não valida apenas aquelas anistias parciais concedidas por comissões como a aplicada na África do Sul, mas também aquelas em que a anistia é total e absoluta, assim como ocorrido no caso do Chile.

Mas será essa a prática a ser adotada pelo TPI?

\subsection{UMA CONCESSÃO DE ANISTIA PODE SER ACEITA PELO TPI COMO "INTERESSE DE JUSTIÇA"?}

Ainda que o Estatuto de Roma aparentemente não permita escape à punição daqueles crimes sob sua competência e não dê azo à possibilidade de anistia dessas mesmas espécies criminosas, tudo pelo que se pode entender das palavras usadas na Convenção de Roma (especialmente do seu preâmbulo), é certo que existe certa flexibilidade no texto para que a anistia possa ser reconhecida em certas circunstâncias ${ }^{55}$. Aponta-se, inclusive, que isso decorreria da "natureza esquizofrênica" das normas do Estatuto, resultantes das várias posições divergentes que se enfrentavam na Convenção de Roma ${ }^{56}$.

De qualquer forma, parece possível entender-se que essa espécie de solução pode ser aceita pelo TPI como satisfatória a fim de garantir a soberania dos Estados pelo reconhecimento da complementaridade. Mesmo que não se possa dizer que as anistias sejam, tecnicamente, exercício de jurisdição criminal, o artigo 53, (2), letra "c" do Estatuto permite que o Procurador (sob os auspícios da Câmara de Instrução) não dê início a um processo quando ele considerar fazê-lo no "interesse da justiça ${ }^{57 " . ~ A i n d a ~ q u e ~ e s s a ~ p o s i c ̧ a ̃ o ~ n a ̃ o ~ s e j a ~}$

${ }^{53}$ DUGARD, John, "Dealing With Crimes of a Past Regime. Is Amnesty Still an Option?', in L.J.I.L. 12-1999, p. 1003.

${ }^{54}$ R. versus Bow Street Metropolitan Stipendiary Magistrate and others, ex parte Pinochet Ugarte (Amnesty International and other intervening) (n. 3), in [1999] 2 All England Law Reports ,p. 97 (HL) e [1999] 38 ILM 581.

${ }_{55}^{5}$ DUGARD, John, op. cit., p. 1014.

${ }_{57}^{56}$ SCHARF, Michael P., op. cit., p. 522.

${ }^{57}$ Diz o artigo 53, parágrafo 2: "2. Se, concluído o inquérito, o Procurador chegar à conclusão de que não há fundamento suficiente para proceder criminalmente, na medida em que: (...) c) $O$ procedimento não serviria o interesse da justiça, consideradas todas as circunstâncias, tais

Revista Brasileira de Direito Internacional, Curitiba, v.1, n.1, jan./jun.2005 
pacífica $^{58}$, ela encontra defensores que entendem perfeitamente possível dito raciocínio quando as ditas comissões e suas conseqüentes anistias garantam paz e configurem-se na melhor opção em uma situação específica de conflito ${ }^{59}$. O que, evidentemente, e especialmente em um caso iniciado, por exemplo, pelo Conselho de Segurança (questões de "paz e segurança ${ }^{60 "}$ ), traduz-se em interesse da justiça.

Em que pese a dúvida sobre o que "interesse da justiça" possa significar $^{61}$, parece certo que essa é a válvula de escape que pode garantir a vigência de uma lei de anistia frente ao Estatuto de Roma. Evidentemente, não em todos os casos. Já se disse que as anistias têm ocorrido no Direito Internacional Penal de duas formas, pelas CVR e pela anistia direta. Alguma das duas permitiria o afastamento da competência do TPI?

Dada a obrigação de julgar que decorre do texto to TPI - e dos muitos textos internacionais mencionados anteriormente - a regra geral é de que anistia alguma pode afastar a possibilidade de atuação do TPI simplesmente porque esse organismo representa o interesse internacional em ver julgados e punidos os responsáveis por crimes universais. Assim, a "justiça, na forma da persecução criminal, precisa ter prioridade sobre a paz e a reconciliação (...) por isso, não se pode permitir que uma CVR ou anistia impeçam o curso da justiça internaciona ${ }^{62 " .}$

Todavia, quando as anistias forem concedidas através de um processo de estabelecimento da verdade, planos de indenização e reconstrução com

como a gravidade do crime, os interesses das vítimas e a idade ou o estado de saúde do presumível autor e o grau de participação no alegado crime, comunicará a sua decisão, devidamente fundamentada, ao Juízo de Instrução e ao Estado que Ihe submeteu o caso, de acordo com o artigo 14, ou ao Conselho de Segurança, se se tratar de um caso previsto no parágrafo b) do artigo 13" (grifamos).

58 DUGARD, John, ibid., p. 1015 and SCHARF, Michael P., op. cit., p. 523.

59 DUGARD, John, Possible Conflicts of Jurisdictions with Truth Commissions, em CASSESE et al. (ed.), The Rome Statute of International Criminal Court: a commentary. 2 v. Oxford: Oxford University Press, 2002, pp. 693-704, p. 703

${ }_{60}^{60}$ Com base no capítulo VII da Carta das Nações Unidas.

${ }^{61}$ Termos como esse, de compreensão difícil e absolutamente subjetiva, podem gerar abusos. Que significados o Direito Internacional pode estar guardando para essa expressão? Qual a conotação política que se the pode ser dada? Não se pode esquecer que por vezes o Direito Internacional abre a sua "loja de horrores" e interpreta incompreensivelmente termos como esse.

62 DUGARD, John, op. cit., p. 702-703.

Revista Brasileira de Direito Internacional, Curitiba, v.1, n.1, jan./jun.2005 
ampla aceitação social e sempre com o fim da pacificação social, então poderão ser excepcionalmente aceitos pelo TPI.

Em situações como essa a decisão de aplicar a complementaridade fica sujeita à idéia de "interesse da justiça", sob o alvitre do Procurador e da Câmara de Instrução, e com várias restrições especialmente referentes aos crimes de genocídio e às Convenções de Genebra ${ }^{63}$. Ainda que as expressões não se traduzam em sinônimos, a "manutenção da paz" é certamente um dos "interesses da justiça". Todavia, repise-se, isso só pode ser admitido em situações especialíssimas. Tome-se como exemplo o caso dos crimes cometidos em Serra Leoa, alguns dos quais estão sendo julgados pela Corte Especial Mista criada pelas Nações Unidas e pelo governo de Serra Leoa. O Conselho de Segurança, na Resolução n. $1315^{64}$, apoiou explicitamente a criação de um "processo de verdade e reconciliação", mas também deixou claro que anistias não podem ser concedidas para crimes de genocídio, crimes contra a humanidade, crimes de guerra e outras graves violações do direito humanitário nacional.

No que se refere às anistias diretas, incondicionais, essa possibilidade não parece ser admissível.

Criadas para proteger os criminosos da punição pela lei, essa espécie de anistia está descomprometida com a realização da verdade. Nesses casos, as anistias são concedidas normalmente sem qualquer vinculação a comissões de verdade, e, quando vinculadas, resumem-se a poucos crimes e a sequer trazer à tona os nomes dos seus perpetradores. Nesses casos, é comum, inclusive, que os próprios criminosos assinem o documento que lhes livrará do peso da lei, ou, ainda, que estejam escondidos nos bastidores, orquestrando às escondidas todo o burlesco ato. Segundo DUGARD, "anistias concedidas aos criminosos por eles mesmos (à la Pinochet) serão ignoradas. Assim também serão as anistias incondicionais. Onde, todavia, a anistia for submetida à aprovação judicial, ou for concedida depois de um processo quase judicial no

\footnotetext{
${ }^{63}$ Idem, p. 703.

${ }^{64}$ Resolução do Conselho de Segurança das Nações Unidas n. 1315, de 14 de agosto de 2000, doc. N. S/RES/1315 (2000), disponível, em inglês, em http://daccessdds.un.org/doc/UNDOC/GEN/N00/605/32/PDF/N0060532.pdf?OpenElement, visitado em 15 de julho de 2006.
}

Revista Brasileira de Direito Internacional, Curitiba, v.1, n.1, jan./jun.2005 
qual o anistiado tiver prestado todas as informações e tiver mostrado que $O$ ato foi cometido com um motivo político e a sociedade em questão tenha submetido o seu passado a escrutínio pela CVR, o promotor poderá, depois de considerar os interesses das vítimas e a gravidade do crime, decidir pelo arquivamento do caso no exercício da sua discricionariedade sob o artigo $53^{65 .}$.

Vale lembrar, ainda, que, evidentemente, nem todos os crimes cometidos em um conflito são de competência internacional. Crimes que não completem os elementos necessários para configurarem-se em genocídios, crimes de guerra ou contra a humanidade (e eventualmente agressão) não são de interesse do Direito Internacional Penal e, portanto, dizem respeito à jurisdição nacional. Tais crimes poderão ser submetidos a julgamentos nacionais ou a leis de anistia na forma que os Estados-membros entenderem adequada - mesmo em competição com crimes sob a jurisdição internacional.

De tudo, fica claro que a regra geral determinada pelo TPI exclui as anistias. Todavia, certa flexibilidade pode ser determinada com fundamento nas entrelinhas do Estatuto de Roma. Quando a anistia corresponder a um processo condicional de pacificação amplo e irrestrito, na forma de uma CVR como aquele levado a cabo pela África do Sul, e a persecução criminal significar um agravo da situação conflituosa em que se aplique, o Procurador do TPI pode deixar de propor o caso sob a salvaguarda do "interesse da justiça", preservando o primeiro sentido da complementaridade. Nos casos de anistias incondicionais como aquelas realizadas no Chile, em que o objetivo é apenas livrar os criminosos da persecução criminal, sem qualquer vinculação com a pacificação ou a abertura da verdade, não há lugar para exceção, e o TPI deverá exercer a sua complementaridade, aplicando a justiça que foi negada pelo Estado parte.

\footnotetext{
${ }^{65}$ DUGARD, John, op. cit, p. 703.
}

Revista Brasileira de Direito Internacional, Curitiba, v.1, n.1, jan./jun.2005 


\section{CONCLUSÃO}

Já se discutiu a importância da complementaridade. A garantia da soberania dos Estados como regra básica de existência e atuação do TPI é sem dúvida um dos seus pontos vitoriosos. O mesmo ocorre com a sua função de catalisador e controlador da aplicação da justiça. Esses elementos são os garantidores do sucesso do Estatuto de Roma e do alto número de ratificações encontrado até agora ${ }^{66}$. Isso é garantia de repressão e prevenção dos crimes que maior sofrimento causam à humanidade.

Essa complementaridade deve zelar pela aplicação efetiva da lei penal nos crimes de competência do Tribunal. E, analisando o TPI por esta ótica, pode-se imaginar que ele poderá vir a ter muito trabalho atuando em um sem número de casos. Talvez, aliás, tenha muito mais atuação funcionando como "verificador" e "confirmador" do direito do que nos casos em que sua jurisdição seja demandada porque os tribunais do país membro se encontram em frangalhos. Por óbvio, parece certo entender-se que é nesse ponto em que residirão os maiores debates sobre a aplicação do TPI. Afinal, é claramente mais complicado - pelo menos no aspecto político - julgar o exercício da soberania de um Estado do que substituí-la. Mas ainda é cedo demais para qualquer tipo de elucubração. Quem viver, verá.

Ao mesmo tempo, a anistia é uma forma viva e constante no Direito Internacional Penal já que vem sendo usada comumente na comunidade internacional. Por isso, não pode ser ignorada pelo TPI. Cedo ou tarde a Corte de Haia terá que enfrentar esse problema e definir se essa solução pode ou não ser admitida como aplicação de justiça.

Do que se apresentou anteriormente, como regra geral as anistias não podem ser admitidas. $O$ esquecimento dos crimes dessa espécie não pode ser imposto à população que passou por tais desgraças. Todavia, tampouco se pode ignorar que por vezes essas anistias são essenciais à manutenção de processos de paz que servem a garantir a reconstrução de uma nação. Em certos casos é de entendimento comum que o melhor é se deixar de punir

${ }^{66}$ O TPI conta, hoje, com 100 ratificações e 139 assinaturas (dados atuais em 15 de julho de 2006).

Revista Brasileira de Direito Internacional, Curitiba, v.1, n.1, jan./jun.2005 
culpados e se agarrar à realização de comissões de verdade e reconciliação, com a conseqüente pacificação social pela revelação da verdade e concessão de indenizações. Há mães que choram - como aquelas da Plaza de Mayo não por perderem seus filhos, mas pelo direito de perdê-los. Afinal, os desaparecidos nos regimes de terror não dão aos seus parentes o sossego que dá a chegada da morte. Essas mães choram apenas para que se reconheça que seus filhos estão realmente mortos!

Assim, em certas circunstâncias, naqueles casos em que a busca pela verdade é essencial e o procedimento criminal pode ser prejudicial ao processo de paz e à tranqüilidade da população, a concessão de anistias parece ser inevitável e provavelmente deverá ser admitida ${ }^{67}$. Obviamente, anistias como aquelas concedidas pelo General Pinochet no Chile, após as barbáries cometidas contra sua própria população serão rechaçadas. Afinal, "anistia incondicional para crimes atrozes não é mais geralmente admitida pela comunidade internacional. Aqui, as CVR podem servir como um útil compromisso para garantir que a justiça não seja totalmente sacrificada em nome da paz ${ }^{68 . "}$. Ou seja, quando, em casos especiais, anistias forem concedidas através de um processo de busca pela verdade e pela paz, o TPI tem fundamentos para entender como válida essa postura nacional.

A aplicação da justiça sempre envolve decisões complexas. Caberá às autoridades do TPI, especialmente ao seu Procurador e à Câmara de Instrução eleger o que parece mais adequado a cada caso concreto: seja a aplicação de justiça criminal, a ferro e fogo, que tem consigo a benesse de garantir a confiança na justiça e reiterar a prevenção geral e especial da pena; seja o reconhecimento da anistia, com a garantia da realização da paz e da reconstrução social.

\footnotetext{
${ }^{67}$ Afinal, "without that incentive the wrongdoer cannot be encouraged to reveal the whole truth which might inherently be against his or her material or proprietary interests ${ }^{67}$. Em The Azanian Peoples Organization (AZAPO) versus the President of the Republic of South Africa, Decisão da Corte Constitucional da África do Sul, caso CCT17/96, decisão em 25 de julho de 1996, p. 35, disponível em http://www.constitutionalcourt.org.za/Archimages/2529.PDF, visitado em 15 de julho de 2006.

6868 DUGARD, John, Dealing With Crimes of a Past Regime. Is Amnesty Still an Option?, in Leiden Journal of International Law (1999), n. 12, pp. 1001-1015, p. 1015.
}

Revista Brasileira de Direito Internacional, Curitiba, v.1, n.1, jan./jun.2005 
Cada caso é, evidentemente, um caso específico e merece análise também específica. "Se as atrocidades estão já ocorrendo, o objetivo mais urgente é (...) levar a violência a um fim imediato. Em seguida, objetivos mais amplos são evitar que tais eventos voltem a acontecer, restaurar a ordem pública, corrigir o comportamento que gerou as violações, reabilitar as vítimas e ofensores, e reconstruir a sociedade de uma forma que se evitem futuras disfunções. A determinação sobre se e em qual extensão punir criminalmente os responsáveis pelos abusos de direitos humanos vai contribuir para o cumprimento de tais objetivos de caráter público é sensível ao contexto de cada circunstância. Para a formulação de uma resposta apropriada, aqueles que tomarão as decisões e seus orientadores devem, então, buscar as raízes dos problemas e colocar os fatores que originam os conflitos sob escrutíniosua história; os autores envolvidos e outros participantes; seus interesses, perspectivas e bases de poder; a localização do conflito; os locais de decisão; e assim por diante ${ }^{69 ",}$.

Nem sempre paz e justiça podem andar de mãos dadas. Seja o "interesse da justiça", então, a lâmina que vai separar essas idéias. Isso não importa. O mais importante, efetivamente, é que essa lâmina seja manejada com maestria, cuidado, hombridade e precisão. Vale recordar a decisão da Corte Constitucional da África do Sul sobre o processo de anistia que teve lugar naquele país, depois do famigerado regime de apartheid:

\footnotetext{
“O resultado, em todos os níveis, é um difícil, sensível, talvez agonizante, balanço entre a necessidade de justiça para as vítimas de abusos passados e a necessidade de reconciliação e rápida transição para um novo futuro; entre o encorajamento aos criminosos para que ajudem na descoberta da verdade e a necessidade de indenização às vítimas de tal verdade; entre a correção do antigo e a criação do novo. É um exercício de imensa dificuldade que interage com uma vasta rede de considerações políticas, emocionais, étnicas e logísticas. É um ato que clama por um julgamento sob responsabilidade daqueles encarregados da criação das leis na era precedente e no período de transição. Os resultados podem muito comumente ser imperfeitos e a busca de tal ato pode dar suporte à mensagem de Kant que afirma que "fora do torto tronco humano, nada direito jamais foi feito". Pode existir um legítimo debate sobre os métodos e mecanismos
}

\footnotetext{
${ }^{69}$ WIESSNER, Siegfried e WILLARD, Andrew R., Policy-Oriented Jurisprudence and Human Rights Abuses in Internal Conflict: Toward a World Public Order of Human Dignity, em RATNER, Steven R. e SLAUGHTER, Anne-Marie, The Methods of International Law. Washington DC: The American Society of International Law (2004), pp. 47-77, p. 56-57.
}

Revista Brasileira de Direito Internacional, Curitiba, v.1, n.1, jan./jun.2005 
adotados pelo legislador para materializar a difícil obrigação que lhe foi outorgada nos termos do epílogo. Nós não estamos aqui para esse debate ou para discutir a sabedoria da escolha desses mecanismos, mas apenas a sua constitucionalidade ${ }^{70,}$.

70 The Azanian Peoples Organization (AZAPO) versus the President of the Republic of South Africa, Decisão da Corte Constitucional da África do Sul, caso CCT17/96, decisão em 25 de julho de 1996, p. 21, disponível em http://www.constitutionalcourt.org.za/Archimages/2529.PDF, visitado em 15 de julho de 2006.

Revista Brasileira de Direito Internacional, Curitiba, v.1, n.1, jan./jun.2005 


\title{
REFERÊNCIAS
}

\author{
BIBLIOGRAFIA
}

BOURDON, Willian. La Cour pénale internationale. Paris: Éditions du Seuil, 2000.

CASSESE, Antonio et al. (ed.), The Rome Statute of International Criminal Court: a commentary. 2 v. Oxford: Oxford University Press, 2002.

, e DELMAS-MARTY, Mireille, "Jurisdictions nationales et crimes

internationaux", Paris: PUF, 2002.

CRYER, Robert, Sudan, Resolution 1593, and International Criminal Justice. Leiden Journal of International Law, Leiden, 2006, n. 19, p. 201.

DUGARD, John. Dealing With Crimes of a Past Regime. Is Amnesty Still an Option?. Leiden Journal of International Law, Leiden, 1999, n. 12, pp. 10011015.

HAYNER, Priscilla B. Unspeakable Truths: confronting state terror and atrocity. London: Routledge, 2001.

KLEFFNER, Jann K. The Impact of Complementarity on National Implementation of Substantive International Criminal Law. Journal of International Criminal Justice, Oxford, Abril de 2003, n. 1, pp. 86-113.

, e KOR, G., (eds.), Complementary Views on Complementarity.

Proceedings of the International Roundtable on the Complementary Nature of the International Criminal Court - Amsterdam, 25/26 June 2004. The Hague:

T.M.C. Asser Press, 2006, p. 79-104.

ORENTLICHER, Diane. Settling Accounts: the Duty to Prosecute Human Rights Violations of a Prior Regime. Yale Law Journal, New Haven, junho de 1991, n. 100, pp. 2537-2615.

RATNER, Steven R. e SLAUGHTER, Anne-Marie. The Methods of International Law. Washington DC: The American Society of International Law (2004).

SCHABAS, William, La Cour criminelle internationale: un pas de plus contre l'impunité. Proceedings $27^{\text {th }}$. Annual Conference October, 15-17, 1998, Canadian Council of International Law, The Impact of International Law on the Practice of Law in Canada. Hague: Kluwer Law International, 1999.

SCHARF, Michael P. The Amnesty Exception to the Jurisdiction of the International Criminal Court. Cornell International Law Journal, Ithaca, 1999, n. 32, pp. 507-527.

Revista Brasileira de Direito Internacional, Curitiba, v.1, n.1, jan./jun.2005 
SUR, Serge. Ver une Cour Penale internationale: la Convention de Rome entre les ONG et le Conseil de Securité. Révue Général de Droit International Public, Paris, 1999, n.2, p. 42.

\section{CASOS MENCIONADOS}

Prosecutor versus Furundzija, Tribunal Criminal Internacional para a exlugoslávia, Câmara de Julgamento, caso IT-95-17/1-T (decisão de 10 de Dezembro de 1998), 39 ILM (1999) 317, especialmente o parágrafo 155.

R. versus Bow Street Metropolitan Stipendiary Magistrate and others, ex parte Pinochet Ugarte (Amnesty International and other intervening) (n. 3). [1999] 2 All England Law Reports, p. 97 (HL) e [1999] 38 ILM 581.

The Azanian Peoples Organization (AZAPO) versus the President of the Republic of South Africa, Decisão da Corte Constitucional da África do Sul, caso CCT17/96, decisão em 25 de julho de 1996, p. 17-19, disponível em http://www.constitutionalcourt.org.za/Archimages/2529.PDF, visitado em 15 de julho de 2006.

Velasquez Rodriguez Case, Judgment of July 29, 1988, Inter-American Court of Human Rights (Ser. C) No. 4 (1988). Disponível em http://www1.umn.edu/humanrts/iachr/b 11 12d.htm. Acesso em 8 de julho de 2006.

Revista Brasileira de Direito Internacional, Curitiba, v.1, n.1, jan./jun.2005 